\title{
BMJ Asthma related to cleaning agents: Open a clinical insight
}

Olivier Vandenplas, ${ }^{1,2}$ Vinciane D'Alpaos, ${ }^{1}$ Geneviève Evrard, ${ }^{1}$ Jacques Jamart, ${ }^{3}$ Joel Thimpont, ${ }^{2}$ François Huaux, ${ }^{4}$ Jean-Christophe Renauld ${ }^{5}$

To cite: Vandenplas 0 , D'Alpaos V, Evrard G, et al. Asthma related to cleaning agents:

a clinical insight. BMJ Open 2013;3:e003568.

doi:10.1136/bmjopen-2013003568

- Prepublication history and additional material for this paper is available online. To view these files please visit the journal online (http://dx.doi.org/10.1136/ bmjopen-2013-003568).

Received 8 July 2013 Revised 8 August 2013 Accepted 9 August 2013

\footnotetext{
${ }^{1}$ Department of Chest Medicine, Centre Hospitalier Universitaire de MontGodinne, Université Catholique de Louvain, Yvoir, Belgium

${ }^{2}$ Fonds des Maladies Professionnelles, Brussels, Belgium

${ }^{3}$ Scientific Support Unit, Centre Hospitalier Universitaire de MontGodinne, Université Catholique de Louvain, Yvoir, Belgium

${ }^{4}$ Industrial Toxicology and Occupational Medicine Unit, Université Catholique de Louvain, Brussels, Belgium ${ }^{5}$ Experimental Medicine Unit, Ludwig Institute for Cancer Research, Université Catholique de Louvain, Brussels, Belgium
}

\section{Correspondence to} Dr Olivier Vandenplas; olivier. vandenplas@uclouvain.be

\section{ABSTRACT}

Objective: To determine the agents causing asthmatic reactions during specific inhalation challenges (SICS) in workers with cleaning-related asthma symptoms and to assess the pattern of bronchial responses in order to identify the mechanisms involved in cleaning-related asthma.

Design: A retrospective case series analysis.

Setting: The study included all participants who completed an SIC procedure with the cleaning/ disinfection products suspected of causing work-related asthma over the period 1992-2011 in a tertiary centre, which is the single specialised centre of the Frenchspeaking part of Belgium where all participants with work-related asthma are referred to for SIC.

Results: The review identified 44 participants who completed an SIC with cleaning/disinfection agents. Challenge exposure to the suspected cleaning agents elicited a $\geq 20 \%$ fall in forced expiratory volume in $1 \mathrm{~s}$ $\left(\mathrm{FEV}_{1}\right)$ in $17(39 \%)$ participants. The cleaning products that induced a positive SIC contained quaternary ammonium compounds $(n=10)$, glutaraldehyde $(n=3)$, both of these agents $(n=1)$ and ethanolamines $(n=2)$. Positive SICs were associated with a significant decrease in the median (IQR) value of the provocative concentration of histamine causing a $20 \%$ fall in $\mathrm{FEV}_{1}$ $\left(\mathrm{PC}_{20}\right)$ from $1.4(0.2-4.2) \mathrm{mg} / \mathrm{mL}$ at baseline to 0.5 $(0.4-3.0) \mathrm{mg} / \mathrm{mL}$ after the challenge and a significant increase in sputum eosinophils from $1.8(0.8-7.2) \%$ at baseline to $10.0(4.1-15.9) \% 7 \mathrm{~h}$ after the challenge exposure while these parameters did not significantly change in participants with a negative SIC. Overall, 11 of 17 participants with positive SICs showed greater than threefold decrease in postchallenge histamine $\mathrm{PC}_{20}$ value, a $>2 \%$ increase in sputum eosinophils, or both of these outcomes.

Conclusions: These data indicate that a substantial proportion of workers who experience asthma symptoms related to cleaning materials show a pattern of bronchial reaction consistent with sensitiser-induced occupational asthma. The results also suggest that quaternary ammonium compounds are the principal cause of sensitiser-induced occupational asthma among cleaners.

\section{INTRODUCTION}

In recent years, there has been a growing concern about the potential role of exposure to cleaning products in the initiation and

\section{ARTICLE SUMMARY}

Strengths and limitations of this study

- This is the first report describing the pattern of functional and sputum cell changes induced by cleaning/disinfection materials. The findings provide further insight into the mechanisms of cleaning-related asthma and may have practical implications for the diagnosis and management of this condition.

- There is a lack of quantitative exposure assessment during the challenge tests.

- The patients described in this report may not accurately represent the whole population of workers with asthma related to cleaning activities; they may represent only a subset of cleaning workers for whom symptoms are severe enough to seek specialised medical advice asthma.

aggravation of asthma. ${ }^{1}{ }^{2}$ Epidemiological surveys have consistently documented increased prevalence $\mathrm{e}^{3-5}$ and incidence ${ }^{6-8}$ rates of asthma in workers exposed to cleaning materials and/or disinfectants, especially in domestic cleaners ${ }^{3}{ }^{4}$ and healthcare workers. ${ }^{9-12}$ In addition, some studies have reported an increased risk of work-related asthma symptoms in exposed workers. ${ }^{5} 1213$

However, there is still limited knowledge on the specific exposures and pathophysiological mechanisms involved in cleaningrelated asthma. ${ }^{1}{ }^{2}$ Cleaning materials typically contain a wide variety of ingredients, some of which are respiratory irritants, such as chlorine-releasing agents and ammonia, while others are potential airway sensitizers. ${ }^{14}{ }^{15}$ Asthma in cleaners has been mostly associated with the irritant effects of cleaning products, which may exacerbate asthma and, at high exposure levels, cause acute irritant-induced asthma (or 'reactive airways dysfunction syndrome'). ${ }^{10}$ 16-19 Nevertheless, occasional case reports have ascribed occupational asthma (OA) due to specific airway hypersensitivty to components of detergents 
or disinfectants. ${ }^{2}$ Overall the determinants of cleaning-related asthma symptoms remain largely uncertain since most available studies have relied on selfreported symptoms or physician-based diagnosis. Only two studies have investigated the effects of cleaning exposures on peak expiratory flow (PEF) variability with inconsistent results. ${ }^{2021}$

Therefore, the data of participants who completed specific inhalation challenges (SICs) with the cleaning agents and/or disinfectants suspected of causing their workrelated asthma symptoms were reviewed in order: (1) to determine the prevalence and causes of asthmatic reactions induced by these agents and (2) to compare the clinical features as well as the changes in non-specific airway hyper-responsiveness (AHR) and sputum cell counts in participants with positive or negative responses to SIC.

\section{METHODS}

This study was a retrospective analysis of the charts of all participants investigated through an SIC in our tertiary centre during the period of 1992-2011 for asthma symptoms related to cleaning products and/or disinfectants. The study was approved by the Comité d'éthique médicale of the Centre Hopitalier Universitaire de Mont-Godinne, approval number 84/2012.

\section{Subjects}

In our centre, SICs with the occupational agent(s) suspected of causing work-related symptoms are routinely performed to diagnose OA provided that the baseline forced expiratory volume in $1 \mathrm{~s}\left(\mathrm{FEV}_{1}\right)$ is equal to or above $60 \%$ of the predicted value. ${ }^{22}$ The participants are referred either by their attending physicians or by the Belgian Workers' Compensation Board (WCB). All French-speaking workers submitting a claim for workrelated asthma to the WCB are referred to our centre in order to perform an SIC procedure.

The participants were those who completed an SIC procedure with cleaning agents and/or disinfectants were identified from a database of 713 participants who underwent an SIC for possible work-related asthma from 1992 up to 2011. Professional cleaners who had been challenged with latex gloves $(n=23)$ or non-cleaning chemicals present at the workplace $(n=3)$ were excluded from this analysis.

\section{Specific inhalation challenges}

SICs were completed according to a standardised protocol, which remained unchanged throughout the study period. ${ }^{23}$ On the first test day, a 'control' challenge was performed by exposing the participants to a paint diluent containing a mixture of alkyl esters, ketones and aromatic hydrocarbons nebulised in a $5 \mathrm{~m}^{3}$ challenge room for $30 \mathrm{~min}$ in order to ensure that fluctuations in $\mathrm{FEV}_{1}$ were $\leq 12 \%$. On the following day(s), the participants were challenged with the cleaning product(s) suspected of causing their asthma symptoms at work.
Exposure to these products was generated through a 'realistic' approach aimed at reproducing as close as possible the conditions of exposure at the workplace. ${ }^{24}$ The tested cleaning materials and the mode of exposure during SIC were selected based on the participants' interview, the Material Safety Data Sheets and, most often, an analysis of the job exposure by WCB"s hygienists. The cleaning agents were diluted in cold or heated water, brushed on a cardboard and/or sprayed according to the collected information.

The duration of exposure to the cleaning products was gradually increased (ie, 1, 4, 10, 15, 30 and $60 \mathrm{~min}$ ) on the same day until a $\geq 20 \%$ fall in $\mathrm{FEV}_{1}$ occurred or a cumulative exposure of $2 \mathrm{~h}$ was completed. Spirometry was obtained at baseline and serially after exposure for a total of at least $6 \mathrm{~h}$. An SIC was considered positive when a sustained $\geq 20 \%$ fall in $\mathrm{FEV}_{1}$ was recorded. The level of AHR to histamine was determined at the end of the control day (ie, baseline value), $7 \mathrm{~h}$ after the end of each active challenge when the $\mathrm{FEV}_{1}$ was within $10 \%$ of baseline value, and $24 \mathrm{~h}$ after the last active challenge. ${ }^{25}$ AHR was expressed as the provocative concentration of histamine causing a $20 \%$ fall in $\mathrm{FEV}_{1}\left(\mathrm{PC}_{20}\right) .^{22}$ Since March 2006, sputum cell counts were assessed at the end of the control day and $7 \mathrm{~h}$ after the end of active challenges (ie, after the assessment of AHR and administration of an inhaled bronchodilator). Sputum was induced through the inhalation of increasing concentrations $(3 \%, 4 \%$ and $5 \%)$ of hypertonic saline and processed as previously described. ${ }^{26}$

Those participants who did not demonstrate a $\geq 20 \%$ fall in $\mathrm{FEV}_{1}$ during the first active test day underwent a repeated challenge for a maximum of $2-3 \mathrm{~h}$ on the next day. Further challenges were proposed when there was greater than threefold decrease in the postchallenge $\mathrm{PC}_{20}$ value or a $>3 \%$ increase in sputum eosinophils as compared to the control day. ${ }^{25} 26$

\section{Data analysis}

The following information was collected from the medical charts: (1) demographic, clinical and occupational characteristics of the participants and (2) baseline functional data, histamine $\mathrm{PC}_{20}$ value on the control day and after the last active challenge, as well as the corresponding sputum cell counts when available. Changes in AHR were considered significant when there was a greater than threefold decrease in postchallenge histamine $\mathrm{PC}_{20}$ compared to baseline value. ${ }^{25}$ An increase in sputum eosinophils of more than two percentage points compared with the control day value was regarded as clinically relevant. ${ }^{25} 27$

Quantitative data are presented as median and 25th and 75th IQR. Comparisons between subgroups of participants were made using the $\chi^{2}$ test, Fisher's exact test or Wilcoxon rank-sum test as appropriate. The Wilcoxon-signed rank test was used for comparing variables before and after SIC in the same participants. All statistical tests were two-tailed; a $p$ value $<0.05$ was 
considered significant. Statistical analysis was performed using the IBM SPSS Statistics V.19.0 software (SPSS Inc, Chicago, Ill inois, USA).

\section{RESULTS}

\section{Baseline characteristics}

During the reviewed period, 44 of 713 (6\%) participants were challenged with cleaning agents and/or disinfectants. The main demographic, occupational and clinical characteristics of the subjects are presented in table 1 . A $\geq 20 \%$ decrease in $\mathrm{FEV}_{1}$ was recorded during SIC in 17 (39\%) of the participants, $24 \%$ showing an isolated immediate reaction, $18 \%$ an isolated late reaction, $29 \%$ dual reactions and $30 \%$ atypical reactions. The proportion of participants referred for possible OA due to cleaning agents among all participants evaluated

Table 1 Demographic, occupational and clinical characteristics of the participants

\begin{tabular}{|c|c|c|c|}
\hline & Positive SIC $(n=17)$ & Negative SIC $(n=27)$ & $p$ Value \\
\hline Gender (female) & $13(76)$ & $23(85)$ & 0.466 \\
\hline Age, years* & $47(39-49)$ & $47(35-53)$ & 0.942 \\
\hline Referral by WCB & $13(76)$ & $20(74)$ & 0.858 \\
\hline \multicolumn{4}{|l|}{ Job/industry } \\
\hline Professional cleaners & 9 & 15 & \\
\hline Healthcare facilities & 2 & 5 & \\
\hline Various industries & 3 & 4 & \\
\hline Private houses & 1 & 3 & \\
\hline Public buildings & 2 & 2 & \\
\hline Kitchens & 1 & 1 & \\
\hline Healthcare workers & 7 & 9 & \\
\hline Food workers & 1 & 2 & \\
\hline Pharmaceutical workers & 0 & 1 & \\
\hline Exposure to respiratory sensitisers & $16(94)$ & $16(59)$ & 0.033 \\
\hline QAC & 10 & 6 & \\
\hline QAC and glutaraldehyde & 1 & 3 & \\
\hline Glutaraldehyde & 3 & 7 & \\
\hline Ethanolamines & 2 & 0 & \\
\hline No identified sensitiser & 1 & 11 & \\
\hline Current and ex-smokers & $6(35)$ & $8(30)$ & 0.694 \\
\hline Atopy $\dagger$ & $7(41)$ & $13(48)$ & 0.651 \\
\hline Asthma pre-existing to exposure & $2(12)$ & $2(7)$ & 0.624 \\
\hline Duration of exposure before the onset of asthma, months* & $12(5-153)$ & $53(31-165)$ & 0.114 \\
\hline Duration of asthma before SIC, months* & $25(7-59)$ & $25(10-55)$ & 0.980 \\
\hline Delay since last work exposure, months* & $10(0.3-16)$ & $8(0.1-24)$ & 0.808 \\
\hline \multicolumn{4}{|l|}{ Work-related respiratory symptoms } \\
\hline Wheezing & $14(82)$ & $14(52)$ & 0.056 \\
\hline Breathlessness & $14(82)$ & $20(74)$ & 0.716 \\
\hline Cough & $11(65)$ & $21(78)$ & 0.343 \\
\hline Chest tightness & $11(65)$ & $18(67)$ & 0.893 \\
\hline Sputum & $4(24)$ & $8(30)$ & 0.740 \\
\hline Work-related rhinitis & $8(47)$ & $16(59)$ & 0.429 \\
\hline Work-related dermatitis & $5(29)$ & $5(19)$ & 0.401 \\
\hline \multicolumn{4}{|l|}{ Inhaled corticosteroid } \\
\hline Number with inhaled corticosteroid & $13(76)$ & $15(56)$ & 0.160 \\
\hline Low dose & $3(18)$ & $5(19)$ & \\
\hline Medium doseł & $5(29)$ & $5(19)$ & 0.494 \\
\hline High doseł & $5(29)$ & $5(19)$ & \\
\hline Short-acting $\beta_{2}$-agonist $\geq$ once a day & $7(41)$ & $1(4)$ & 0.002 \\
\hline Baseline $\mathrm{FEV}_{1}, \%$ predicted ${ }^{*}$ & $92(73-101)$ & $100(88-109)$ & 0.049 \\
\hline Baseline $\mathrm{FEV}_{1} / \mathrm{FVC}, \%^{*}$ & $71(63-77)$ & $80(73-83)$ & 0.002 \\
\hline Baseline airway obstruction§ & $5(29)$ & $1(4)$ & 0.016 \\
\hline \multicolumn{4}{|c|}{ 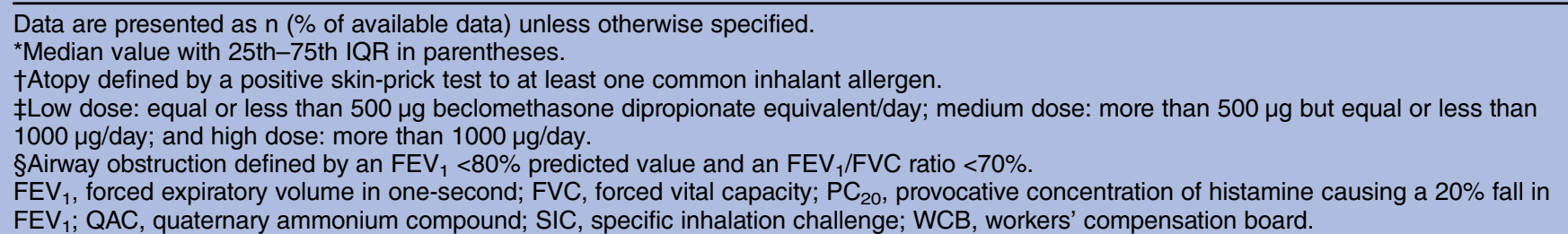 } \\
\hline
\end{tabular}


through an SIC procedure in our centre increased from $3.2 \%$ (10 of 316) during the period 1992-2001 to $8.6 \%$ (34 of 397, $\mathrm{p}=0.003$ ) from 2002 to 2011. The vast majority of the participants with a positive SIC (16 of 17) had been evaluated during the last decade (2002-2011).

The median (IQR) duration of exposure to cleaning agents that elicited an asthmatic reaction was 120 (32150) $\mathrm{min}$. The cleaning products that induced a positive $\mathrm{FEV}_{1}$ response contained quaternary ammonium compounds (QAC) (mainly, benzalkonium and didecyldimethylammonium chlorides) in $10(59 \%)$ participants, glutaraldehyde in three instances, both agents in one instance and ethanolamines in two participants (table 1). No known sensitising agent was identified in one participant who had been challenged with a cleaning product that contained sodium octylsulfate, nitrilotriacetic acid and potassium hydroxide.

The participants who developed an asthmatic response to cleaning agents and/or disinfectants did not differ from those who did not for most of the demographic and clinical characteristics. The pattern of the workrelated respiratory symptoms was similar in both groups (table 1), although wheezing at work was slightly more frequently reported by participants with a positive SIC $(82 \%$ vs $52 \%, \mathrm{p}=0.056)$. The participants with a positive SIC tended to experience a lower level of asthma control. The proportion of these participants who required the use of an inhaled short-acting $\beta_{2}$-agonist at least once a day was significantly higher $(41 \%)$ as compared to those with a negative SIC (4\%; $\mathrm{p}=0.002)$, although the daily dose of inhaled corticosteroids were similar in both groups. In addition, baseline spirometry revealed more often significant airway obstruction in participants who showed a positive SIC (29\%) than in those who did not $(4 \%, \mathrm{p}=0.016)$.

\section{Non-specific airway hyper-responsiveness}

At baseline, the participants with a positive SIC to cleaning products showed a significantly lower median histamine $\mathrm{PC}_{20}$ value than those with a negative SIC $(\mathrm{p}=0.004$; table 2$)$. Among the 27 participants with a negative SIC, 13 (48\%) failed to demonstrate significant airway hyper-responsiveness (ie, histamine $\mathrm{PC}_{20}$ value $>16 \mathrm{mg} / \mathrm{mL}$ ) at the prechallenge assessment. These participants differed from the 14 participants with a histamine $\mathrm{PC}_{20}$ value $\leq 16 \mathrm{mg} / \mathrm{mL}$ only by a longer duration of work-related asthma symptoms before the SIC (47 (21-70) months vs 19 (6-41) months, $\mathrm{p}=0.036)$.

A postchallenge histamine $\mathrm{PC}_{20}$ value was available in 12 of the 17 participants who showed a positive SIC and in 25 of 27 participants with a negative SIC. The postchallenge $\mathrm{PC}_{20}$ value was not measured because the $\mathrm{FEV}_{1} 24 \mathrm{~h}$ after the end of exposure was still $\geq 20 \%$ lower than the prechallenge value in four participants with a positive SIC or because the participants refused to complete the test in the other instances. Positive SICs were associated with a significant decrease in the median postchallenge $\mathrm{PC}_{20}$ value, whereas no change

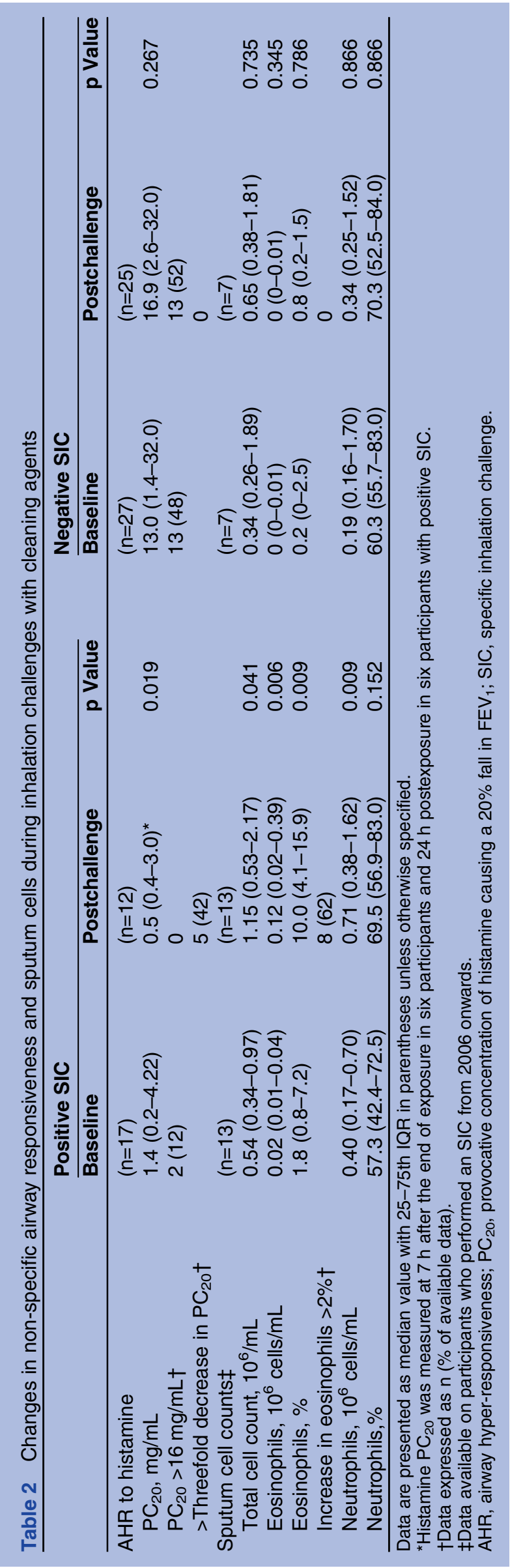


was documented in participants with a negative SIC. Five of the $12(42 \%)$ participants with a positive SIC demonstrated agreater than threefold decrease in postchallenge $\mathrm{PC}_{20}$ value, while none of those with a negative SIC did so.

\section{Sputum cell counts}

Among the participants who were investigated from 2006 onwards, a suitable sputum sample was obtained $7 \mathrm{~h}$ after the end of the last active challenge in 13 of 15 positive SICs and in 7 of 11 negative SICs (table 2). At baseline, the participants with a positive SIC showed a slightly higher sputum eosinophil percentage than those with a negative SIC $(\mathrm{p}=0.046)$. Positive SICs were associated with a significant postchallenge increase in sputum eosinophils, while eosinophil counts did not significantly change in negative SICs. Eight $(62 \%)$ of the 13 participants with a positive SIC showed a $>2 \%$ increase in postchallenge eosinophils, while none of the participants with a negative SIC did so. In participants with a positive SIC, there was an increase in the absolute number of sputum neutrophils after the last active challenge while the percentage of neutrophils was not significantly different at baseline and on the last challenge day.

Overall, positive SICs were associated with either a greater than threefold decrease in postchallenge $\mathrm{PC}_{20}$ value in three participants, a $>2 \%$ increase in sputum eosinophils in six participants or both of these outcomes in two participants.

\section{DISCUSSION}

This study showed that challenge exposure to the cleaning agents and/or disinfectants used at work induced an asthmatic reaction in $39 \%$ of the participants who experienced asthma symptoms on exposure to these products. In addition, the results of the SICs provided evidence supporting a specific hypersensitivity mechanism rather than a non-specific bronchoconstriction due to an irritant effect. Indeed, $11(65 \%)$ of the 17 positive SICs induced by cleaning agents were associated with a significant increase in postchallenge AHR, an increase in sputum eosinophils or both of these outcomes. Noticeably, among the participants who developed a positive bronchial response to QACs, a postchallenge increase in sputum eosinophils and/or in the level of AHR was documented in 9 of 10 instances.

To the best of our knowledge, this is the first study reporting the changes in lung function parameters and markers of airway inflammation in participants challenged with the cleaning materials suspected of causing work-related asthma symptoms. Available evidence indicates that cleaning materials can both exacerbate asthma (ie, work-exacerbated asthma) and induce the development of asthma (ie, OA) through either immunological or irritant mechanisms. ${ }^{12} 161928$ Medina-Ramon et $a t^{20}$ investigated the daily changes in PEF in 43 female domestic cleaners with a recent history of asthma and/or chronic bronchitis. There was no significant association between the changes in PEF and cleaning exposures, with the exception of a decrease in PEF at night that was related to the use of ammonia. Nevertheless, analysis of PEF data using the Occupational Asthma System programme identified a work-related pattern in $30 \%$ of the participants, but the specific exposures associated with these changes were not described. By contrast, Bernstein et $a l^{21}$ reported an increase in lower respiratory tract symptoms during cleaning activities in asthmatic homemakers compared with non-asthmatics in the absence of significant changes in PEF. Our findings in participants with a positive SIC are consistent with previous studies which reported that an increase in AHR and sputum eosinophils occurs specifically-though inconstantly-in sensitised individuals who develop asthmatic reactions induced by common inhalant allergens as well as high-molecular-weight and low-molecular-weight occupational agents. ${ }^{29}$ Only one participant developed a $\geq 20 \%$ fall in $\mathrm{FEV}_{1}$ on exposure to a degreasing spray that apparently did not contain a known sensitising agent. This participant who reported pre-existing asthma, also failed to demonstrate a postchallenge increase in AHR or sputum eosinophils, suggesting that the bronchial response resulted from an irritant effect consistent with the concept of 'work-exacerbated asthma'.

Noticeably, 13 participants with a negative SIC showed AHR to histamine neither at baseline nor after challenge exposure to the cleaning agents (table 2), although nine of them were treated with an inhaled corticosteroid. These findings are consistent with those reported by Chiry et al who found that a high proportion (57\%) of participants referred to tertiary centres for work-related asthma symptoms failed to demonstrate any functional evidence of asthma, although they experienced respiratory symptoms that were similar to those diagnosed as having OA or work-exacerbated asthma, except for a lower prevalence of wheezing. ${ }^{31}$ A recent populationbased questionnaire survey of healthcare workers exposed to cleaning materials also found that a high proportion $(64 \%)$ of the participants who experienced work-related asthma symptoms had not been given a diagnosis of asthma. ${ }^{12}$

There is little information on the specific agents involved in the various phenotypes of asthma related to cleaning exposure. Most epidemiological studies have linked asthma with exposure to irritant cleaning materials, mainly bleach, ${ }^{9} 11121728$ ammonia $^{911} 122028$ and cleaning/degreasing sprays. ${ }^{9} 111220$ On the other hand, occasional case reports have described OA presumably due to specific sensitisation to disinfectants, such as chloramine-T, glutaraldehyde, QACs and isothiazolinone, surfactants, ethanolamines used in wax-removing compounds and detergent enzymes. ${ }^{1}{ }^{2}$ Among the cases of asthma related to cleaning products identified by the US Sentinel Event Notification Systems for Occupational Risks (SENSOR), 62\% were considered as 'OA with a 
latency period', but only $14 \%$ of these cases were related to an identified respiratory sensitizer. ${ }^{16}$ A recent Finnish report described 20 cases of OA diagnosed in professional cleaning workers using SIC during the period $1994-2004 .^{32}$ The majority $(70 \%)$ of these cases were caused by moulds and non-cleaning chemicals (eg, isocyanates) that were present at the workplace, whereas only six cases of OA were attributed to cleaning agents, including ethanolamines and chloramine-T. Our study focusing on the role of cleaning products and/or disinfectants indicates that QACs are the most frequent agents causing $\mathrm{OA}$ in workers exposed to such materials in various occupations. Very few cases of $\mathrm{OA}$ due to QACs have been reported in the literature, ${ }^{33} 34$ although these compounds are widely used in cleaning products. ${ }^{14}{ }^{15}$ QACs are non-volatile, but it is likely that inhalation exposure may occur during spray application of the products. ${ }^{14} 15$ The immunological mechanisms involved in the development of specific airway hypersensitivity to QACs is unknown as it is the case for most low-molecular-weight occupational agents. ${ }^{29}$

The major limitation of this study results from the lack of quantitative exposure assessment during the SICs. The agents that induced the observed asthmatic reactions could not be formally identified since the participants were challenged with the commercial products they used at work, which most often contained a mixture of various potentially sensitising and irritant compounds. The causal agents could only be inferred from their known asthmagenic potential. The asthma hazard index of QACs (0.81-0.95), glutaraldehyde (0.82) and ethanolamines (0.64-0.86) derived from a quantitative structure activity relationship model is above the cut-off value of 0.5 , which predicts the potential for inducing OA with a sensitivity of $86 \%$ and a specificity of $99 \%$ (Seed MJ, personal communication; http://www.coeh.man.ac.uk/ research/asthma/; last accessed 28 Jan 2012). ${ }^{35}$

The participants described in this report may not accurately represent the whole population of workers with asthma related to cleaning activities. The data were derived from the single specialised centre of the French-speaking part of Belgium ( 1.7 million active workers) where all SICs were performed during the period from 1992 to 2011. However, the participants evaluated in this study may represent only a subset of cleaning workers for whom symptoms are severe enough to seek specialised medical advice or claim compensation. It is likely that domestic cleaners were largely under-represented in our series since most private home cleaners are employed in the informal sector and are not eligible for compensation. Failure to refer workers with possible cleaning-related asthma to our tertiary centre may also result from under-recognition of the condition by healthcare providers and reluctance of workers to seek medical advice for work-related symptoms because of concerns about adverse professional and financial consequences, as already outlined for work-related asthma in general. ${ }^{36}$ However, facilities for performing an objective assessment of work-related asthma are easily available in Belgium, SIC procedures are paid by the WCB, and those workers who qualify for compensation are entitled to receive several types of financial awards, which are better than those obtained from the national health insurance. Noteworthy, the study focused on individuals who experienced workrelated asthma symptoms that were directly related to cleaning products and/or disinfectants; those with symptoms related to workplace agents other than cleaning products were not included in this study.

This study did not allow for estimating the incidence of OA among workers exposed to cleaning/disinfection materials. Indeed, the number of workers exposed to these agents in the French-speaking part of Belgium could not be accurately determined since the participants with cleaning-related asthma were employed in a wide spectrum of occupations and industrial sectors. Despite their inherent limitations, the data yield some suggestion as to a recent increase in OA caused by cleaning/disinfection materials, since most cases in our series were evaluated during the last 10 years of the study period.

\section{CONCLUSION}

This study based on SICs indicates that a substantial proportion of participants who experience asthma symptoms related to cleaning materials actually suffer from sensitizer-induced OA, predominantly caused by QACs. The findings of this study may help to improve the diagnosis, management and prevention of cleaning-related asthma, although further investigation is required to identify the underlying pathophysiological mechanisms.

Acknowledgements The authors are grateful to Maria Roccaro-Luczak, Michael Duchene and Stéphane François from the Fonds des Maladies Professionnelles, Brussels, Belgium who performed most of the job exposure assessments. They also thank James Hatch for reviewing the manuscript.

Contributors OV, JT, JCR and FH were involved in conception of the study, interpretation of the data and reviewing of the manuscript. VD, GE and JJ were involved in data collection, analysis of data and reviewing of the manuscript. OV supervised specific inhalation challenges, drafted the initial version of the manuscript and is the guarantor of the final content of the manuscript.

Funding This work was supported by a grant from the Actions de Recherche Concertées de la Communauté Française de Belgique.

Competing interests None.

Provenance and peer review Not commissioned; externally peer reviewed.

Data sharing statement Extra data are available by emailing olivier. vandenplas@uclouvain.be

Open Access This is an Open Access article distributed in accordance with the Creative Commons Attribution Non Commercial (CC BY-NC 3.0) license, which permits others to distribute, remix, adapt, build upon this work noncommercially, and license their derivative works on different terms, provided the original work is properly cited and the use is non-commercial. See: http:// creativecommons.org/licenses/by-nc/3.0/

\section{REFERENCES}

1. Zock JP, Vizcaya D, Le Moual N. Update on asthma and cleaners. Curr Opin Allergy Clin Immunol 2010;10:114-20. 
2. Quirce S, Barranco P. Cleaning agents and asthma. J Investig Allergol Clin Immunol 2010;20:542-50; quiz 2p following 50.

3. Zock JP, Kogevinas M, Sunyer J, et al. Asthma risk, cleaning activities and use of specific cleaning products among Spanish indoor cleaners. Scand J Work Environ Health 2001;27:76-81.

4. Medina-Ramon M, Zock JP, Kogevinas M, et al. Asthma symptoms in women employed in domestic cleaning: a community based study. Thorax 2003;58:950-4.

5. Arif AA, Delclos GL, Whitehead LW, et al. Occupational exposures associated with work-related asthma and work-related wheezing among US workers. Am J Ind Med 2003;44:368-76.

6. Karjalainen A, Martikainen R, Karjalainen J, et al. Excess incidence of asthma among Finnish cleaners employed in different industries. Eur Respir J 2002;19:90-5.

7. Kogevinas M, Zock JP, Jarvis D, et al. Exposure to substances in the workplace and new-onset asthma: an international prospective population-based study (ECRHS-II). Lancet 2007;370:336-41.

8. Ghosh RE, Cullinan P, Fishwick D, et al. Asthma and occupation in the 1958 birth cohort. Thorax 2013;68:365-71.

9. Mirabelli MC, Zock JP, Plana E, et al. Occupational risk factors for asthma among nurses and related healthcare professionals in an international study. Occup Environ Med 2007;64:474-9.

10. Delclos GL, Gimeno D, Arif AA, et al. Occupational risk factors and asthma among health care professionals. Am J Respir Crit Care Med 2007;175:667-75.

11. Vizcaya D, Mirabelli MC, Anto JM, et al. A workforce-based study of occupational exposures and asthma symptoms in cleaning workers. Occup Environ Med 2011;68:914-19.

12. Arif AA, Delclos GL. Association between cleaning-related chemicals and work-related asthma and asthma symptoms among healthcare professionals. Occup Environ Med 2012;69:35-40.

13. Obadia M, Liss GM, Lou W, et al. Relationships between asthma and work exposures among non-domestic cleaners in Ontario. Am J Ind Med 2009;52:716-23.

14. Wolkoff $P$, Schneider T, Kildeso J, et al. Risk in cleaning: chemical and physical exposure. Sci Total Environ 1998;215:135-56.

15. Bello A, Quinn MM, Perry MJ, et al. Characterization of occupationa exposures to cleaning products used for common cleaning tasks-a pilot study of hospital cleaners. Environ Health 2009;8:11.

16. Rosenman KD, Reilly MJ, Schill DP, et al. Cleaning products and work-related asthma. J Occup Environ Med 2003;45:556-63.

17. Medina-Ramon M, Zock JP, Kogevinas M, et al. Asthma, chronic bronchitis, and exposure to irritant agents in occupational domestic cleaning: a nested case-control study. Occup Environ Med 2005;62:598-606.

18. Orriols R, Costa R, Albanell M, et al. Reported occupational respiratory diseases in Catalonia. Occup Environ Med 2006;63:255-60.

19. Vizcaya D, Mirabelli MC, Orriols R, et al. Functional and biological characteristics of asthma in cleaning workers. Respir Med 2013;107:673-83.

20. Medina-Ramon M, Zock JP, Kogevinas M, et al. Short-term respiratory effects of cleaning exposures in female domestic cleaners. Eur Respir J 2006;27:1196-203.
21. Bernstein JA, Brandt D, Rezvani M, et al. Evaluation of cleaning activities on respiratory symptoms in asthmatic female homemakers. Ann Allergy Asthma Immunol 2009;102:41-6.

22. Sterk PJ, Fabbri LM, Quanjer PH, et al. Airway responsiveness. Standardized challenge testing with pharmacological, physical and sensitizing stimuli in adults. Report Working Party Standardization of Lung Function Tests, European Community for Steel and Coal. Official Statement of the European Respiratory Society. Eur Respir J Suppl 1993;16:53-83.

23. Vandenplas $\mathrm{O}$, Malo JL. Inhalation challenges with agents causing occupational asthma. Eur Respir J 1997;10:2612-29.

24. Pepys J, Hutchcroft BJ. Bronchial provocation tests in etiologic diagnosis and analysis of asthma. Am Rev Respir Dis 1975;112:829-59.

25. Vandenplas O, Delwiche JP, Jamart J, et al. Increase in non-specific bronchial hyperresponsiveness as an early marker of bronchial response to occupational agents during specific inhalation challenges. Thorax 1996;51:472-8.

26. Vandenplas O, D'Alpaos V, Heymans J, et al. Sputum eosinophilia: an early marker of bronchial response to occupational agents. Allergy 2009;64:754-61.

27. Girard F, Chaboillez S, Cartier A, et al. An effective strategy for diagnosing occupational asthma: use of induced sputum. Am $J$ Respir Crit Care Med 2004;170:845-50.

28. de Fatima Macaira E, Algranti E, Medina Coeli Mendonca E, et al. Rhinitis and asthma symptoms in non-domestic cleaners from the Sao Paulo metropolitan area, Brazil. Occup Environ Med 2007:64:446-53.

29. Maestrelli P, Boschetto P, Fabbri LM, et al. Mechanisms of occupational asthma. J Allergy Clin Immunol 2009;123:531-42; quiz 43-4.

30. Nicholson PJ, Cullinan P, Taylor AJ, et al. Evidence based guidelines for the prevention, identification, and management of occupational asthma. Occup Environ Med 2005;62:290-9.

31. Chiry S, Boulet LP, Lepage J, et al. Frequency of work-related respiratory symptoms in workers without asthma. Am J Ind Med 2009;52:447-54.

32. Makela R, Kauppi $\mathrm{P}$, Suuronen $\mathrm{K}$, et al. Occupational asthma in professional cleaning work: a clinical study. Occup Med (Lond) 2011;61:121-6.

33. Burge PS, Richardson MN. Occupational asthma due to indirect exposure to lauryl dimethyl benzyl ammonium chloride used in a floor cleaner. Thorax 1994;49:842-3.

34. Purohit A, Kopferschmitt-Kubler MC, Moreau C, et al. Quaternary ammonium compounds and occupational asthma. Int Arch Occup Environ Health 2000;73:423-7.

35. Seed M, Agius R. Further validation of computer-based prediction of chemical asthma hazard. Occup Med (Lond) 2010;60:115-20.

36. Fishwick D, Bradshaw L, Davies J, et al. Are we failing workers with symptoms suggestive of occupational asthma? Prim Care Respir J 2007;16:304-10.

37. Santos MS, Jung H, Peyrovi J, et al. Occupational asthma and work-exacerbated asthma: factors associated with time to diagnostic steps. Chest 2007;131:1768-75. 